\title{
Dienos conjugados y malondialdehído como indicadores de lipoperoxidación en semen de toros "Carora"
}

\author{
Flores, C. ${ }^{\text {; }}$ Márquez, Y.'; Vilanova, L. ${ }^{2}$; Mendoza, C. ${ }^{1}$ \\ ${ }^{1}$ Unidad de Investigación en Ciencias Funcionales Dr. Haity Moussatché (UNIHM), ${ }^{2}$ Departamento de Genética \\ y Reproducción Animal, Facultad de Ciencias Veterinarias, Universidad Centroccidental "Lisandro Alvarado" \\ (UCLA), Barquisimeto (Lara, Venezuela). Tel. 0251-2592630. E-mail: caf06@hotmail.com.
}

\begin{abstract}
Resumen
Flores, C.; Márquez, Y.; Vilanova, L.; Mendoza, C.: Dienos conjugados y malondialdehído como indicadores de lipoperoxidación en semen de toros "Carora". Rev. vet. 22: 2, 91-94, 2011. Las elevadas temperaturas ambientales incrementan la producción de radicales libres y causan desbalances en los mecanismos antioxidantes. De esta manera se altera el metabolismo celular, lo que repercute en la función reproductiva del macho, con eventuales alteraciones de la capacidad fecundante de los espermatozoides. El objetivo de esta investigación fue determinar el grado de lipoperoxidación en semen de toros "Carora" en praderas de la región centroccidental de Venezuela, durante dos años consecutivos en los cuales se registraron temperatura ambiental, humedad y precipitaciones. Se utilizaron 9 toros de 3 a 4 años de edad. El semen se obtuvo con vagina artificial y se preservó a $-20^{\circ} \mathrm{C}$. Mediante métodos convencionales se obtuvieron los niveles de dienos conjugados (DC) y malondialdehído (MDA), que fueron analizados estadísticamente mediante el test " $\mathrm{t}$ " $(\mathrm{p} \leq 0,05)$. Los niveles de DC fueron de $0,00109 \pm 0,00012 \mathrm{nmol} / \mathrm{mg}$ de proteínas en el primer año (lluvioso) y $0,00210 \pm 0,00030 \mathrm{nmol} / \mathrm{mg}$ de proteínas en el segundo año (sequía), siendo la diferencia estadísticamente significativa. En cambio, los niveles seminales de MDA $(9,32 \pm 2,365$ y $7,17 \pm 0,510 \mathrm{nmol} / \mathrm{mg}$ de proteínas en primer y segundo año respectivamente), no registraron diferencias significativas. El aumento de los niveles de DC (peroxidación en fase inicial) se atribuye a la menor calidad de los pastos por falta de desarrollo debido a insuficientes lluvias del segundo año.
\end{abstract}

Palabras clave: toro, semen, lipoperoxidación, estrés oxidativo.

\begin{abstract}
Flores, C., Márquez, Y.; Vilanova, L., Mendoza, C.: Conjugated dienes and malondialdehyde as indicators of lipid peroxidation in semen of "Carora" bulls. Rev. vet. 22: 2, 91-94, 2011. High environmental temperatures increase the free radical production and cause abnormalities in the anti-oxidant mechanisms. As a consequence the cellular metabolism is altered and the male reproductive function is affected, with eventual alterations of the fertilizing capacity of spermatozoa. The objective of this research was to determine the lipoperoxidation level in semen of "Carora" bulls grazing in prairies of Venezuela's central-west region, during two consecutive years for which environmental temperature, humidity and precipitations were registered. Nine bulls from 3 to 4 years old were used. Semen was obtained by artificial vagina and was preserved at $-20^{\circ} \mathrm{C}$. Using conventional methods, the levels of conjugated dienes (CD) and malondialdehyde (MDA) were obtained and statistically analyzed by means of the " $\mathrm{t}$ " test $(\mathrm{p}<0.05)$. The $\mathrm{CD}$ levels were $0.00109 \pm 0.00012 \mathrm{nmol} / \mathrm{mg}$ of proteins in the first year (rainy) and $0.00210 \pm 0.00030 \mathrm{nmol} / \mathrm{mg}$ of proteins in the second year (drought). Difference resulted statistically significant. On the other hand, MDA seminal levels $(9.32 \pm 2.365$ and $7.17 \pm 0.510 \mathrm{nmol} / \mathrm{mg}$ of proteins in first and second year, respectively), did not register significant differences. The increase of CD levels (peroxidation in initial phase) is attributed to the poor quality of grasses due to insufficient rains during the second year.
\end{abstract}

Key words: bull, semen, lipid peroxidation, oxidative stress. 


\section{INTRODUCCIÓN}

La mayoría de los organismos vivos necesita oxígeno para obtener la energía necesaria para sus requerimientos diarios. Durante su utilización se generan especies reactivas intermedias o radicales libres (RL), los cuales deben ser atenuados por diferentes sistemas de defensa antioxidante, que involucran enzimas y moléculas, estas últimas aportadas por la dieta ${ }^{2}$. Cuando la liberación de radicales libres excede a los mecanismos antioxidantes se presenta una situación celular conocida como estrés oxidativo, el cual induce daño molecular a nivel de los lípidos de la membrana plasmática (lipoperoxidación) y en consecuencia, alteración de la permeabilidad de las membranas, evento que puede ser detectado por la determinación de dienos conjugados (DC) y malondialdehido (MDA) ${ }^{5}$.

Bajo condiciones tropicales, un metabolismo intenso ocasiona aumento del consumo de oxígeno, lo cual genera incrementos de la producción de radicales libres, que pueden superar los mecanismos antioxidantes. Esta situación se agrava ante el consumo de dietas deficientes en sustancias antioxidantes ${ }^{4}$. Las vacas lecheras, debido a su alto metabolismo y a los cambios climáticos, son susceptibles al estrés calórico durante el cual su temperatura corporal se eleva hasta $41^{\circ} \mathrm{C}$, situación que conduce a alteraciones de la función celular ${ }^{9}$. A nivel reproductivo se ha determinado que las altas temperaturas ambientales pueden ocasionar alteración de los ovocitos e infertilidad en vacas ${ }^{3}$.

Las especies reactivas de oxígeno (ROS) tienen la capacidad de alterar reversible o irreversiblemente la función celular ${ }^{6} \mathrm{y}$ en el semen el estrés oxidativo se relaciona con daño de los espermatozoides y disminución de la calidad seminal ${ }^{16}$. La administración de antioxidantes poseería efecto protector al evitar el daño que producen estos agentes ${ }^{6}$. En el semen, las ROS son producidas por los espermatozoides ${ }^{20} \mathrm{y}$ juegan un papel fundamental durante la capacitación espermática y la reacción acrosómica, fenómenos controlados por mecanismos antioxidantes enzimáticos y no enzimáticos. Sin embargo, desbalances entre la producción de ROS y antioxidantes podrían ocasionar cuadros severos de infertilidad ${ }^{8}$.

Por otro lado, la alta concentración de ácidos grasos poliinsaturados de las membranas plasmáticas de los espermatozoides los torna muy susceptibles a sufrir lipoperoxidación ${ }^{14}$. En tal sentido, se afirma que altos niveles de RL aumentan la permeabilidad de la membrana plasmática del espermatozoide ocasionando anomalías en su morfología y problemas de fertilidad ${ }^{19}$. En el semen de pacientes con infecciones de las glándulas sexuales, los RL provienen tanto de los espermatozoides defectuosos como de los leucocitos seminales ${ }^{13}$. La producción elevada de ROS se asocia a pérdida de la función espermática a través de mecanismos que incluyen lipoperoxidación, alterando la permeabilidad de la membrana plasmática, la motilidad espermática y en definitiva afectando directamente la capacidad fecundante del semen ${ }^{5,12}$.
La región centroccidental de Venezuela es una zona semiárida, con bajas precipitaciones y altas temperaturas. Tal situación ambiental puede afectar el metabolismo del oxígeno y afectar las concentraciones de ROS en el semen del ganado bovino, que en caso de superar a los mecanismos antioxidantes puede ocasionar estrés oxidativo y posible disminución de la calidad seminal. Con el objetivo de corroborar tal situación en toros de raza "Carora" (ganado adaptado a dicha región) se decidió tomar muestras de semen durante dos años consecutivos cuyos niveles de precipitación fueran diferentes y determinar en cada uno las concentraciones de indicadores de lipoperoxidación lipídica (DC y MDA).

\section{MATERIAL Y MÉTODOS}

Animales, muestras. Se trabajó con semen de toros "Carora", raza proveniente de la cruza de bovinos Pardo Suizo con ganado criollo de la región centroccidental de Venezuela. Se dispuso de 9 toros de 3 a 4 años de edad, con fertilidad probada, provenientes del Centro de Inseminación Artificial de Carora (Venezuela). Los ejemplares bajo ensayo se mantuvieron estabulados, con alimentación a base de concentrado $(4 \mathrm{~kg} /$ día/animal), silo de cáscara de naranja, forraje verde y agua ad libitum. La recolección de semen se realizó mensualmente durante dos años consecutivos mediante la utilización de vagina artificial, preservándose la muestra a $-20^{\circ} \mathrm{C}$ hasta su procesamiento.

Determinación de indicadores de estrés oxidativo. Los dienos conjugados, que son los productos iniciales del proceso de lipoperoxidación, fueron extraídos con isopropanol y valorados por la técnica de Wallin ${ }^{19}$. El malondialdehído, producto final del proceso de lipoperoxidación, se determinó mediante el test para sustancias reaccionantes con el ácido 2-tiobarbitúrico acorde al método de Ohkawa ${ }^{10}$. Las proteínas totales se evaluaron utilizando el kit BioRad (Richmond, USA).

Registros climatológicos. Los datos climatológicos (temperatura, humedad ambiental, precipitaciones) se extrajeron de registros climatológicos oficiales (Central La Pastora). La contabilización de los dos años de estudio comenzó a partir de la fecha de la primera toma de muestras. Así, el año 1 se inició en julio de 2005 y culminó en junio de 2006; el año 2 desde julio de 2006 hasta junio de 2007.

Análisis estadístico. Para el análisis de los resultados se realizó estadística descriptiva obteniéndose media aritmética y desviación estándar, para posteriormente realizar de una prueba " $t$ " con un nivel de significancia del $95 \%$.

\section{RESULTADOS}

Durante el primer año de estudio (julio 2005-junio 2006) las precipitaciones totalizaron $1.454 \mathrm{~mm}$, mientras que en el segundo año (julio 2006-junio 2007) sumaron $972 \mathrm{~mm}$ (diferencia: $482 \mathrm{~mm}$ ). En cada año se evidenciaron dos épocas bien marcadas, siendo los me- 
Tabla 1. Niveles de DC y MDA según el año.

\begin{tabular}{ccc}
\hline año & DC nmol/mg prot. & MDA nmol/mg prot. \\
\hline 1 & $* 0,00109 \pm 0,00012$ & $9,32 \pm 2,365$ \\
2 & $* 0,00210 \pm 0,00030$ & $7,17 \pm 0,510$ \\
\hline
\end{tabular}

DC: dienos conjugados, MDA: malondialdehido.

*asteriscos indican diferencia significativa $(\mathrm{p} \leq 0,05)$.

ses de marzo, abril, mayo, agosto, septiembre, octubre y noviembre los de mayor precipitación. Los meses de junio, julio, diciembre, enero y febrero correspondieron al período de sequía. La temperatura fluctuó desde 25,67 a $26,39^{\circ} \mathrm{C}$ y la humedad relativa ambiente osciló entre 55,59 y $57,20 \%$.

Como muestra la Tabla 1, los niveles seminales de DC durante el primer año de estudio presentaron una media de $0,00109 \pm 0,00012 \mathrm{nmol} / \mathrm{mg}$ de proteínas y durante el segundo año fue de $0,00210 \pm 0,00030 \mathrm{nmol} /$ $\mathrm{mg}$ de proteínas, niveles que difirieron estadísticamente de manera significativa $(p<0,05)$. Se desprende que los niveles más altos de DC se registraron en el segundo año, cuando las precipitaciones fueron escasas. Las concentraciones seminales de MDA fueron de 9,32 \pm $2,365 \mathrm{nmol} / \mathrm{mg}$ de proteínas durante el primer año y $7,17 \pm 0,510 \mathrm{nmol} / \mathrm{mg}$ de proteínas durante el segundo, sin diferencia estadísticamente significativa.

\section{DISCUSIÓN}

Los RL se consideran moléculas que en su estructura atómica presentan un electrón desapareado o impar en su orbital externo, lo que les confiere una configuración espacial altamente inestable, capaz de combinarse inespecíficamente con diversas moléculas integrantes de la estructura celular: carbohidratos, lípidos, proteínas y ácidos nucleicos ${ }^{11}$.

El espermatozoide, como toda célula, aprovecha sus nutrientes (carbohidratos, lípidos y proteínas) a través de procesos oxidativos, obteniendo energía para mantener su viabilidad y funciones. Uno de los procesos más importantes es el que se lleva a cabo en la mitocondria a través de la cadena respiratoria, principal fuente de ATP y $\operatorname{ROS}^{18}$.

Los espermatozoides bovinos están pobremente adaptados al metabolismo de $\mathrm{H}_{2} \mathrm{O}_{2}$ (ROS) y factores como la criopreservación disminuyen significativamente la cantidad de la enzima superóxido dismutasa, hasta en un $50 \%{ }^{6}$ y generan estrés oxidativo a causa del agotamiento de los mecanismos antioxidantes y al aumento en la producción de ROS. Estos últimos causan daño en los espermatozoides por lipoperoxiedación, la cual se traduce en cambios ultraestructurales, bioquímicos y funcionales en las células espermáticas, con pérdida de viabilidad y disminución de la fertilidad ${ }^{18}$.

En esta investigación se observaron diferencias significativas en los valores de DC entre los dos años de estudio, cuyos niveles más altos se registraron en el segundo año (lipoperoxidación inicial), época durante la cual las precipitaciones fueron más bajas, con la con- secuente deficiencia de sustratos alimentarios (antioxidantes) por reducción de la cantidad y calidad de las pasturas ${ }^{7}$. Estudios colaterales realizados en nuestro laboratorio (aún no publicados) revelaron para el segundo año disminución del volumen seminal, motilidad y vitalidad espermáticas, con incremento del porcentaje de anomalías en el semen de los animales estudiados.

Se estima que estos hallazgos deberían atribuirse a los cambios que los ROS producen en la permeabilidad de la membrana plasmática de los espermatozoides, lo cual ocasiona alteración del patrón de movimiento espermático y cambios morfológicos por inhibición de la actividad de algunas enzimas, tales como glucosa 6 fosfato deshidrogenasa ${ }^{15}$. En coincidencia, otros investigadores confirmaron que la peroxidación de los lípidos de la membrana de los espermatozoides correlaciona con la disminución de la motilidad espermática y con los defectos morfológicos irreversibles de los gametos masculinos ${ }^{1}$.

El aumento de ROS habitualmente se asocia a condiciones climáticas de altas temperaturas ${ }^{4}$. Si esta producción no es controlada de manera efectiva por los mecanismos antioxidantes se establece el estrés oxidativo ${ }^{20}$, situación que puede inducir cambios en la fisiología espermática y afectar la capacidad fecundante del semen ${ }^{17}$. Sin embargo, este estudio se desarrolló bajo condiciones ambientales de confort para los animales, con humedad relativa del $55-57 \%$ y temperatura ambiental de $25-26^{\circ} \mathrm{C}$, por lo cual no creemos que estos factores climáticos hayan influido significativamente en el aumento de la producción de ROS. Obviamente, el cambio climático más importante del segundo año fue la disminución de las lluvias, del 56,74\%. En los sistemas de cría extensiva es corriente que las sequías afecten significativamente la producción ganadera ${ }^{7}$.

A manera de colofón debe enfatizarse que existen escasos estudios que aborden el estrés oxidativo de las células espermáticas por deficiencia de sustratos alimentarios. Resulta necesario profundizar los conocimientos sobre la producción de ROS en tales casos, caracterizando causas y efectos en semen fresco y criopreservado, para establecer medidas que contrarresten el daño seminal y optimicen la producción animal.

\section{REFERENCIAS}

1. Alba L, Monzón G, Peláez L, Quintero Y. 2000. Papel del estrés oxidativo en la infertilidad masculina. Rev Cub Invest Biomed 19: 202-205.

2. Albiés J. 2007. Estrés oxidativo y su relación con el aporte de antioxidantes nutricionales en pacientes críticos. Tesis Doctoral, Universidad de Granada (España), p 10-16.

3. Al-Katanani YM, Paula-Lopes FF, Hansen PJ. 2002. Effect of season and exposure to heat stress on oocyte competence in Holstein cows. J Dairy Sci 85: 390-396.

4. Arechiga CF, Vazquez S, Ortiz O, Hernández J, Porras A, McDowell LR, Hansen PJ. 1998. Effect of injection of $\beta$-carotene or vitamin $\mathrm{E}$ and selenium on fertility of lactating dairy cows. Theriogenology 50: 65-76. 
5. Baker MA, Aitken RJ. 2005. Reactive oxygen species in spermatozoa: methods for monitoring and significance for the origins of genetic disease and infertility. Reprod Biol Endocrinol 3: 67-75.

6. Gallardo J. 2007. Evolución del sistema antioxidante en el semen normal. Rev Invest Clin 59: 42-47.

7. Homse AC. 2007. Efecto de la sequía sobre la producción ganadera regional. http://www.inta.gov.ar/mercedes/ investiga/noticias/noticias\%20tecnicas/informeSequiaHomse.pdf.

8. Lewis SE, Boyle PM, McKinney KA, Younj IS, Thompson W. 1995. Total antioxidant capacity of seminal plasma is different in fertility and infertility men. Fertil Steril 64: 868-870.

9. Lopes FF, Hansen PJ. 2002. Apoptosis is an adaptive response in bovine preimplantation embryos that facilitates survival after heat shock. Biochem Biophys Res Comm 295: 37-42.

10. Ohkawa H, Ohishi N, Yagi K. 1979. Assay for lipid peroxides in animal tissues by thiobarbituric acid reaction. Anal Biochem 95: 351-358.

11. Quintero W, Mallea L, Machado A, Llópiz N, Céspedes E, Monzón G, Yepes S. 2000. Efecto del estrés oxidativo sobre la calidad del semen de pacientes infértiles con leucocitospermia. Rev Cub Invest Biomed 19: 183-185.

12. Rodríguez J, Menéndez J, Trujillo Y. 2001. Radicales libres en la biomedicina y estrés oxidativo. Rev Cub Med Milit 30: 36-44.
13. Sikka SC, Rajasekaran M, Hellstrom WJ. 1995. Role of oxidative stress and antioxidants in male infertility. $J$ Androl 16: 464-481.

14. Tortolero I, Arata-Bellabarba G, Osuna J, Gómez R, Regadera J. 2005. Estrés oxidativo y función espermática. Rev Venez Endocrinol Metab 3: 12-19.

15. Villa N, Ceballos A. 2007. Radicales libres e infertilidad en el macho. Vet Zoot 1: 87-97.

16. Villa N, Moreno W, Ceballos A. 2008. Especies reactivas del oxígeno en espermatozoides: los métodos de control y la importancia de los orígenes genéticos de la enfermedad y la infertilidad. Rev Colomb Cienc Pec 21: 50-55.

17. Villa C. 2009. Enfoques sobre semen, estrés oxidativo y antioxidantes. Taurus (Buenos Aires) 11: 34-38.

18. Wallin B, Rosengren B, Shertzer H, Camejo G. 1993. Lipoprotein oxidation and measurement of thiobarbituric acid reacting substances formation in a single microtiter plate: its use for evaluation of antioxidants. Anal Biochem 208: $10-15$.

19. Yeni D, Gundogan M, Cigerci I, Avdatek F, Fida F. 2010. Seasonal variation of oxidative stress parameters in seminal plasma. J Anim Vet Adv 9: 49-54.

20. Zimi A, De Laryrade E, Gognan C. 1993. Reactive oxygen species in semen of infertile patients: level of SOD and catalase-like activities in seminal plasma and spermatozoo. Inf J Androl 16: 193-188.

\section{Revista Veterinaria obtuvo el máximo nivel de categorización del CAICYT-CONICET}

Tras el pertinente proceso de evaluación según criterios de calidad editorial, en setiembre de 2005 CAICYT-CONICET ha clasificado a nuestra publicación con Categoría 1 (nivel superior de excelencia), con lo cual pasa a integrar el Catálogo Latindex (folio 14022). La Dirección de Revista veterinaria agradece a quienes colaboraron para obtener tan importante distinción. Ver: http://www.latindex. unam.mx/busquedas/catalogotitulo.html 